\title{
Genes of the Drosophila maternal dorsal group control the specific expression of the zygotic gene twist in presumptive mesodermal cells
}

\author{
Bernard Thisse, Corinne Stoetzel, Mariam El Messal, and Fabienne Perrin-Schmitt \\ Laboratoire de Génétique Moléculaire des Eucaryotes du CNRS, Unité 184 de Biologie Moléculaire et de Génie Génétique de \\ l'INSERM, Faculté de Médecine, 67085 Strasbourg Cédex, France
}

\begin{abstract}
At least 10 maternally active genes, the dorsal-group genes, and two zygotically active genes, twist and snail, encode information for the establishment of the dorso-ventral axis in Drosophila embryos. Mutation in any one of these genes results in partial or total dorsalization of the embryo. Twist mutants show partial dorsalization and a failure of mesoderm differentiation. Using in situ hybridization, we show that most twist transcripts are detected in the cells forming the ventral furrow at gastrulation and, later, in the cells forming the embryonic mesoderm. A specific interaction between dorsal and twist has already been described, and we show that the expression of $t w i s t$ is not only abolished in embryos descended from homozygous dorsal females but also in embryos developing from eggs laid by females homozygous for the maternal dorsalizing mutations, pelle, easter, and Toll.
\end{abstract}

[Key Words: twist; mesoderm; control; dorsal group; expression; maternal genes]

Received May 27, 1987; revised version accepted July 21, 1987.

Some of the positional information required for the definition of the antero-posterior and dorso-ventral axes in Drosophila embryos is already present at egg deposition. Until $2 \mathrm{hr}$ after oviposition, only maternal genes, or their products, are active. A set of approximately 10 such genes is known to be involved in the establishment of the dorso-ventral embryonic pattern, the dorsal group (Anderson and Nüsslein-Volhard 1984). Eggs laid by females homozygous for a mutation in one of these genes are "dorsalized," that is, structures normally made only in the dorsal part of the embryo are formed in all regions of the mutant embryo (Lohs-Schardin et al. 1979|.

Later in development (from $2 \mathrm{hr}$ after oviposition onward), a set of zygotic genes is necessary for completing the dorso-ventral pattern. Two such genes, twist (twi) and snail (sna), have been identified (Nüsslein-Volhard et al. 1984). Mutation of these genes results in a very early deviation from normal development, the lack of ventral furrow formation during gastrulation. twi is a homozygous zygotic lethal that causes a partial dorsalization of embryos and a failure of mesoderm differentiation (Nüsslein-Volhard et al. 1984). The phenotype of mutant twi embryos is similar to that of embryos derived from eggs laid by heterozygous dorsal ( $d l$ ) females at high temperature, described as the "dorsal-dominant phenotype" $\left(d l^{D}\right)$ by Nüsslein-Volhard (1979).

A specific synergism between the maternal action of $d l$ and the zygotic action of twi has been described (Simpson 1983). Briefly, at or above $25^{\circ} \mathrm{C}$, twi heterozygotes show a dominant lethal effect in embryos derived from heterozygous $d l$ females, whereas no such effect was observed with any other mutant of the dorsal group.

$t w i$ is located at $100 \mathrm{cM}$ on chromosome $2 \mathrm{R}$. We have recently cloned the region containing the twi gene (Thisse et al. 1987) and have studied the expression of twi during early embryogenesis. The presence of $t w i$ RNA was readily detected between 2 and $6 \mathrm{hr}$ after oviposition, with a peak between 2 and $4 \mathrm{hr}$, that is, at about the time of gastrulation. Approximately 10-fold less twi RNA could be detected in 8- to 10-hr embryos, and none thereafter. Using in situ hybridization to tissue sections of frozen wild-type embryos (Hafen et al. 1983), we have visualized the spatial distribution of the $t w i$ transcripts and their time of appearance. twi appears to be specifically expressed in the cells that are situated ventrally at cellular blastoderm and that invaginate a few minutes later to form the ventral furrow of the early gastrula. Later, the transcripts are located within the presumptive mesoderm of the embryo. We have also studied the effect of some genes of the maternal dorsal group on the expression of $t w i$ and show that $t w i$ RNA 
Thisse et al.
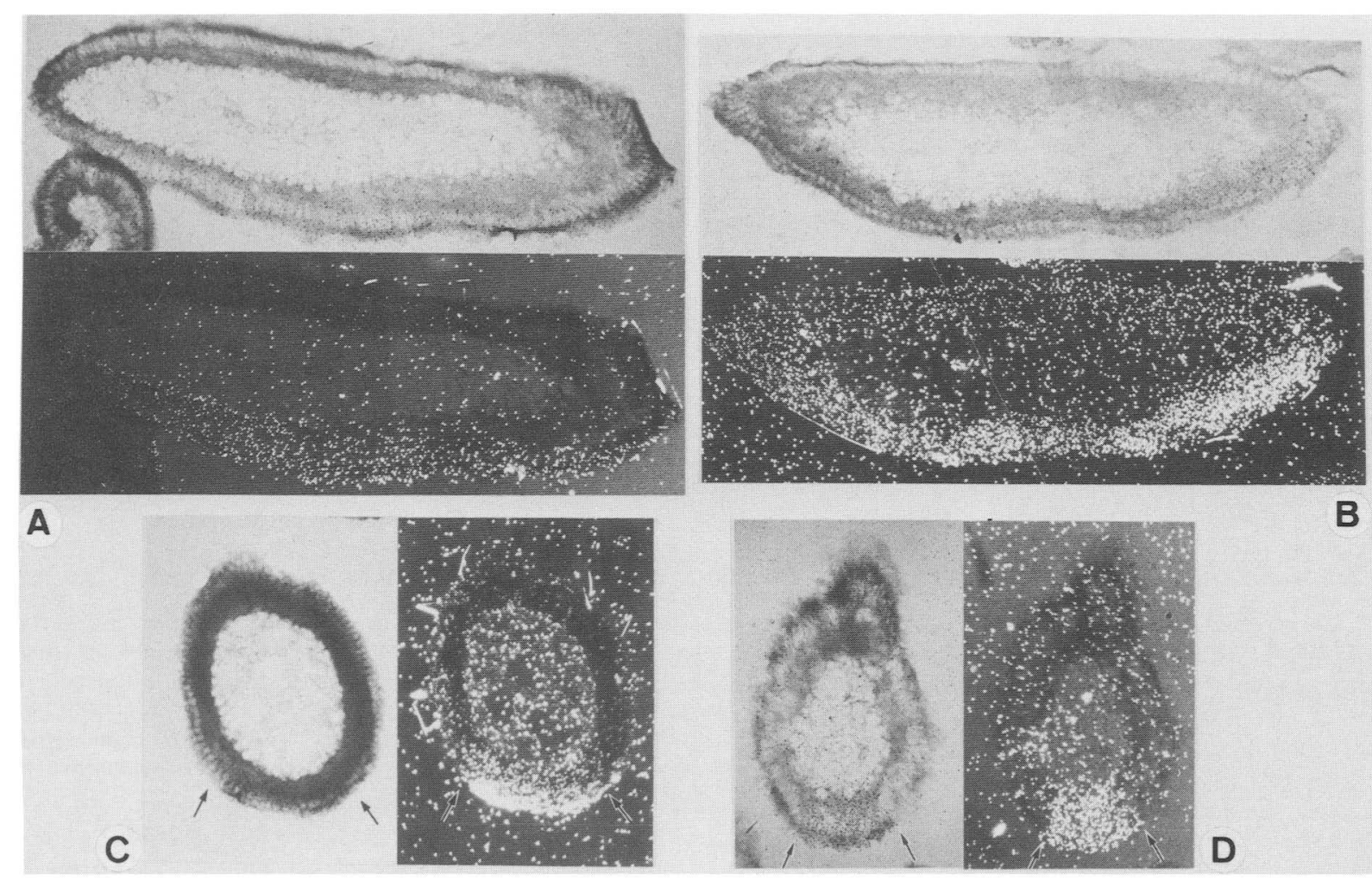

B

Figure 1. Localization of the twi transcripts in tissue sections of embryos at cellular blastoderm (stage 5). Photomicrographs of the same embryos taken under phase-contrast or dark-field illumination. $(A$ and $B)$ Parasagittal sections through embryos at cellular blastoderm; $(C$ and $D)$ transverse sections through embryos at about the same stage. The sections are oriented with the embryonic dorsal side up, and with the anterior end to the left (for sagittal sections). The arrows in $C$ and $D$ delimit the ventral cells, which show twi transcript accumulation. Autoradiographic exposure, 1 month.

cannot be detected in embryos developing from eggs laid by females homozygous for either pelle, easter, Toll-recessive, or $d l$.

\section{Results}

\section{twi RNA transcripts at late cellular blastoderm-early gastrula stages}

After fertilization, the zygotic nucleus begins to undergo divisions, resulting in the formation of a syncytium. The nuclei then migrate to the periphery of the developing egg at about $90 \mathrm{~min}$ after egg deposition. Soon after, the peripheral nuclei elongate perpendicularly to the surface of the egg, and cell membranes begin to form. At 150 min, preblastoderm divisions are completed, and the embryo consists of a single layer of about 6000 columnar peripheral cells that envelops a mass of yolk (Zalokar and Erk 1976). Immediately after cellular blastoderm formation, gastrulation begins. The earliest signs of gastrulation are the changes of form and orientation of the cells situated ventrally (Campos-Ortega and Hartenstein
1965). Using a twi cDNA probe (see Materials and methods|, the expression of $t$ wi is detected by in situ hybridization in the ventral cells of cellular blastoderm at about stage 5 (see Campos-Ortega and Hartenstein 1985) (Fig. 1A,B); and in some sections, it appears that there may be more transcripts in the posterior part of the embryo. Cross sections show that the expression of $t w i$ is localized in a discrete number of ventral cells (see Fig. $1 C, D)$. A few minutes later, the ventral furrow forms along the antero-posterior axis of the embryo, and the ventral cells invaginate to form the presumptive mesoderm. Various transverse sections of embryos at stage 6 indicate that hybridization is localized to the invaginated cells of the ventral furrow (Fig. 2). In Figure 2, B and $\mathrm{C}$ (transverse sections of the middle or posterior part of embryos), only the presumptive mesodermal cells located in the ventral part of the embryo show high twi RNA accumulation (cf. ectoderm labeling). In sections from the anterior part of embryos (Fig. 2A for an oblique section; Fig. 2D for a transverse section/, no twi expression is seen in cells forming the cephalic furrow or the

Figure 2: Various transverse sections through gastrulating embryos. Photomicrographs of the different embryos, each presented under bright-field and dark-field illumination. Dorsal side is up. $(A)$ An oblique section; $(D)$ a transverse section through the anterior part of embryos. No twi transcripts are detected in ectoderm (ec) and cephalic furrow (cf), whereas twi RNA is accumulating in presumptive mesodermal cells $(\mathrm{ms})$. ( $B$ and $C)$ Transverse sections through the mid-part or posterior part of gastrulating embryos: $t w i$ RNAs are detected in the invaginated cells (ms) of the ventral furrow. No transcripts in ec. Autoradiographic exposure, 1 month. 

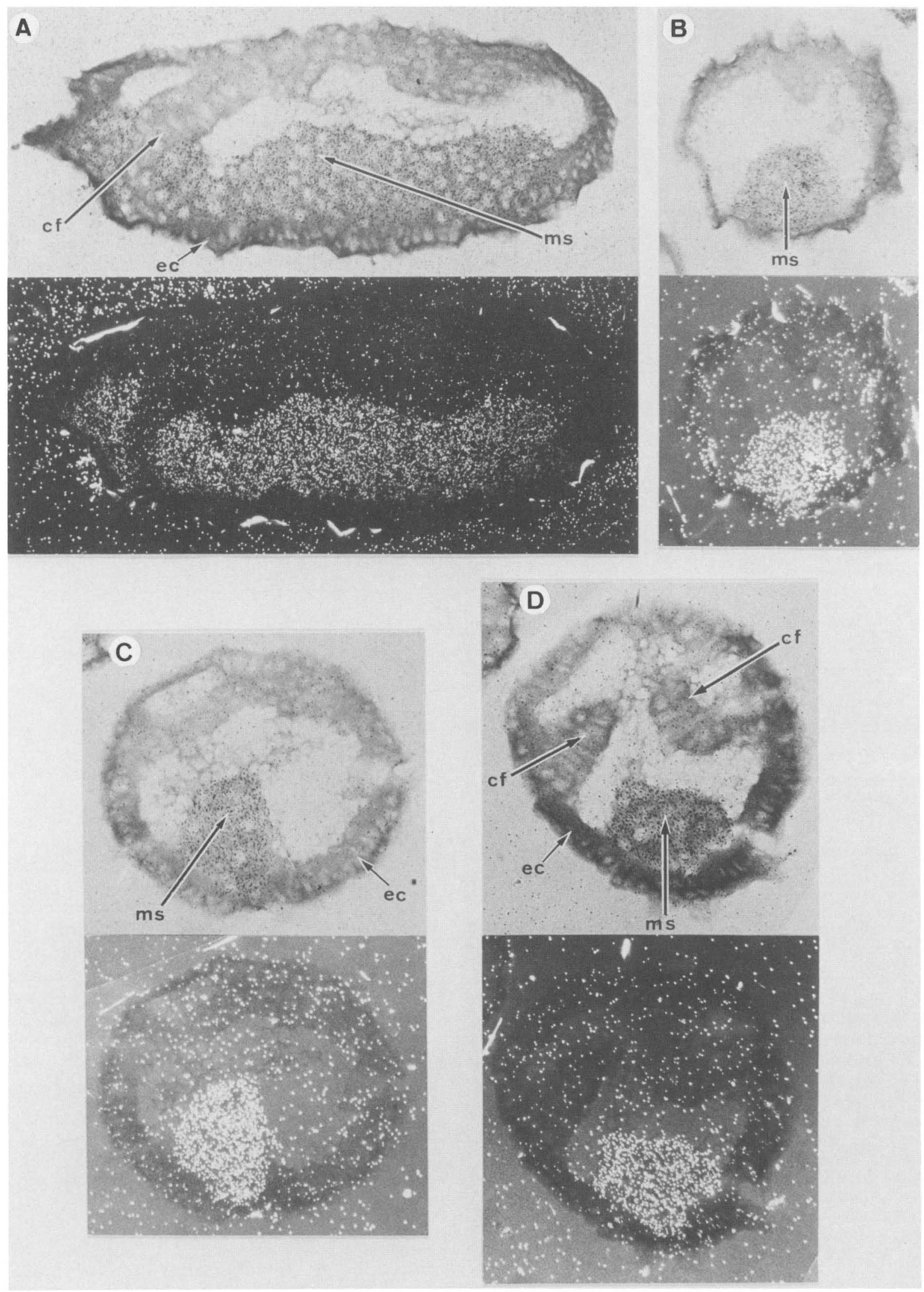

Figure 2. (See facing page for legend.) 
ectoderm, whereas the presumptive mesodermal cells show high levels of $t w i$ RNA accumulation. Serial longitudinal sections have been examined, and their analysis confirms that $t w i$ RNA accumulates specifically along the ventral mid-part of the gastrulating embryo (presumptive mesodermal cells). The hybridization signal follows the elongation of the ventral furrow from the posterior part of the embryo and covers the whole ventral side.

We were unable to orientate embryos before embedding, but the examination of hybridized serial sections obtained at different angles is always consistent with an abundant expression of $t w i$ in the cells forming the ventral furrow.

\section{twi RNA transcripts at late gastrulation-germ band extension stages}

At the beginning of stage 8, the internal layer of unorientated cells situated ventrally (the germ band) begins to migrate around the caudal pole toward the dorsal side of the embryo, whereas cells situated at the posterior pole migrate dorsally and begin to invaginate to form the posterior midgut rudiment.

At late state $8, t w i$ is expressed in the mesodermal layer of the germ band, whereas almost no hybridization occurs either in the posterior midgut rudiment or in the anterior midgut rudiment (Fig. 3). The twi RNA, therefore, seems to be produced intensively in the cells that will produce mesodermal tissues and organs. Later stages have not yet been studied systematically.

\section{The maternal $\mathrm{dl}^{+}$function is necessary for twi expression}

In view of the known genetic interaction between $d l$ and $t w i$ (see introductory section and Discussion), we have investigated whether $t w i$ is transcribed correctly in embryos developing from eggs laid by homozygous $d l$ females. Eggs were collected from homozygous and heterozygous $d 1^{1}$ females during successive 2 -hr periods $\left[d l^{1}\right.$ is a strong allele, showing the most extreme mutant phenotype (Anderson and Nüsslein-Volhard 1986)]. After incubation of the eggs at $25^{\circ} \mathrm{C}$ for the appropriate

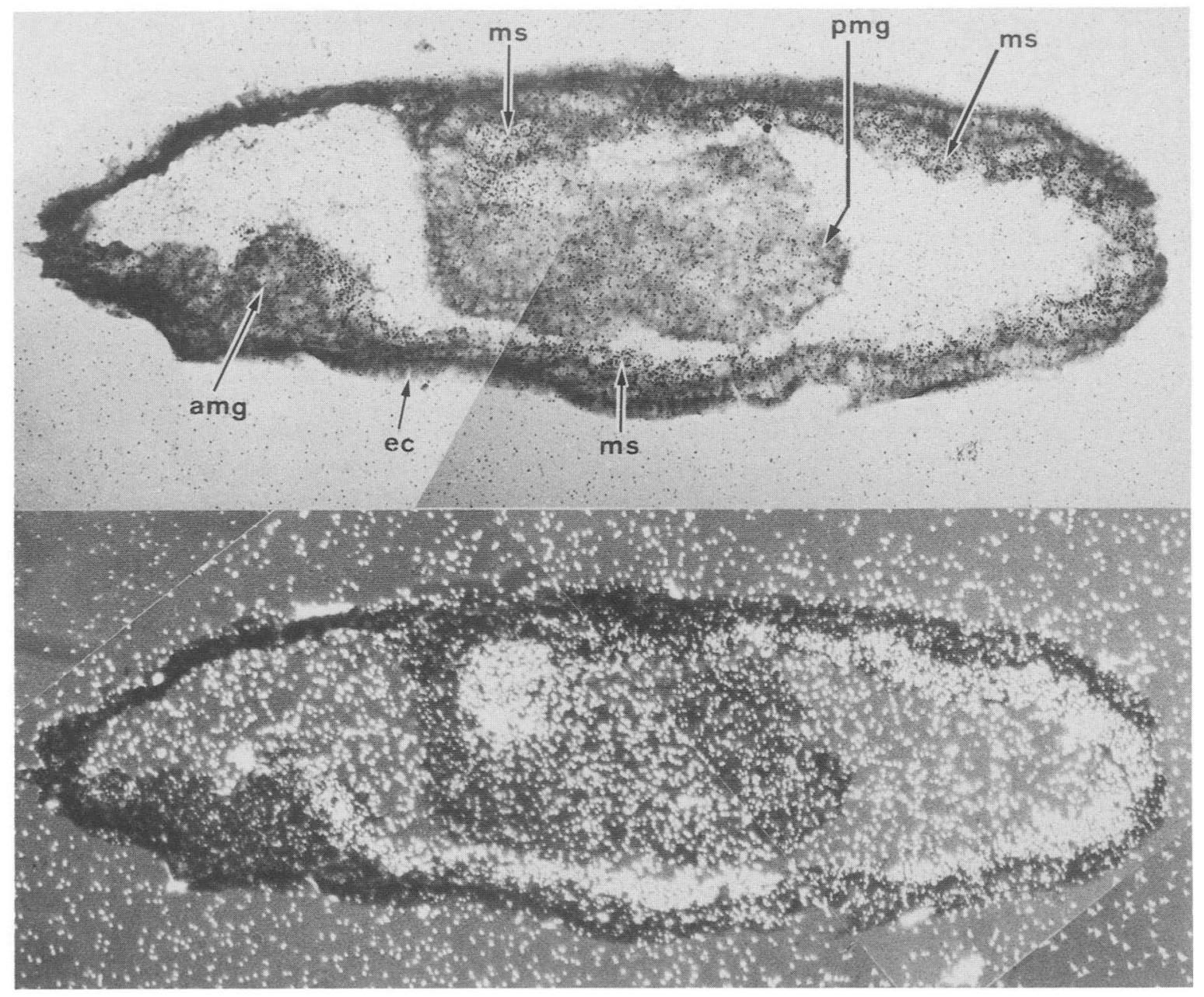

Figure 3. Localization of $t w i$ transcripts on a section of an extended germ band-stage embryo. The embryo is oriented with anterior part to the left and dorsal side up. Parasagittal section. Dark-field illumination shows the hybridization pattern of the ${ }^{3} \mathrm{H}-\mathrm{labeled} t w i$ cDNA probe. Autoradiographic exposure, 1 month. Abbreviations: (ms) presumptive mesoderm; (ec) ectoderm; (ang) anterior midgut; (pmg) posterior midgut. The accumulation of $t w i$ RNA is obvious in the ms, although there is a high level of background in this photomicrograph. 
time, the total and poly $(\mathrm{A})^{+}$RNAs were extracted and analyzed by Northern blotting using the $t w i-c D N A$ probe. In Figure 4A, lanes 1-4 correspond to total RNA, and lanes 5-8 to poly $(\mathrm{A})^{+}$RNAs. The $t w i$ expression in RNA extracted from 2- to 4-hr wild-type embryos is shown in lanes 2 and 6. No twi RNA could be detected in 2- to 4-hr RNA extracted from embryos descended from homozygous $d l$ mutant females (lanes 4 and 8 ). The same filter shows RNA extracted from 0 - to 2 -hr wildtype embryos (lanes 1 and 5) where twi RNA begins to appear (lane 5), whereas RNAs extracted from 0 - to 2-hr embryos derived from eggs laid by homozygous $d l \mathrm{mu}-$ tant females do not contain any $t w i$ transcripts. An actin 5C DNA clone was hybridized as a control to the same filter (see Fig. 4A'). Bands of similar intensities are observed in lanes $1-4$ and 5-8 for total RNA and poly $(A)^{+}$ RNA, respectively. Double arrowheads point to the 1.95and $1.75-\mathrm{kb}$ actin RNAs, indicating that RNA from a housekeeping gene is present at the same level in all samples. We estimate that even if $1 \%$ of $t w i$ RNA were present in the embryos descended from the homozygous dl females, it would have been detected [cf. the intensities of the signals in lanes 2 (total RNA) and 6 (poly(A) ${ }^{+}$RNA); poly $(\mathrm{A})^{+}$RNA is estimated to be $\sim 5 \%$ of total RNA $\left.{ }^{+}\right]$. In 2- to 4-hr embryos developing at $25^{\circ} \mathrm{C}$ from eggs laid at $25^{\circ} \mathrm{C}$ by heterozyous $d l$ females, the amount of twi RNA seems similar or slightly reduced when compared to that seen in wild-type embryos (not shown). Precise quantifications have not been done. We also hybridized a fushi tarazu (ftz) probe (a gift of W. McGinnis) to the same RNA samples extracted from embryos descended from homozygous $d l$ females, so as to analyze the level of expression of a developmental gene that does not belong to the dorso-ventral system. $f t z$ was expressed at the same level as in wild type, both in embryos derived from eggs laid by homozygous and heterozygous $d l$ females (not shown). Thus, with regard to only the amounts of RNA transcribed (we did not check their distribution), at least one housekeeping gene (actin 5C) and another developmental gene that does not belong to the dorso-ventral system (ftz) are correctly expressed in embryos derived from homozygous $d l$ females.

\section{Mutations in other genes implied in the dorso-ventral} pattern establishment also alter expression of twi

A working model for the establishment of the dorsoventral pattern was proposed by Anderson et al. (1985a), in which the role of some of the dorsal maternal genes is to activate the product of the Toll gene which, in combination with the $d l$ gene product, would lead to the presence of a "morphogen." From all available genetic data on the dorso-ventral pattern formation, it is clear that each of the gene products of each of the dorsal-group maternal genes acts independently, but all are required for correct positional information in the embryo. Anderson and Nüsslein-Volhard (1986) divided the maternal genes into two classes, the early and the late genes. We restricted our studies to some of the late genes, as we were in search of genes that would be more directly implied in controlling the twi zygotic gene expression. We therefore extracted total RNA from 2- to

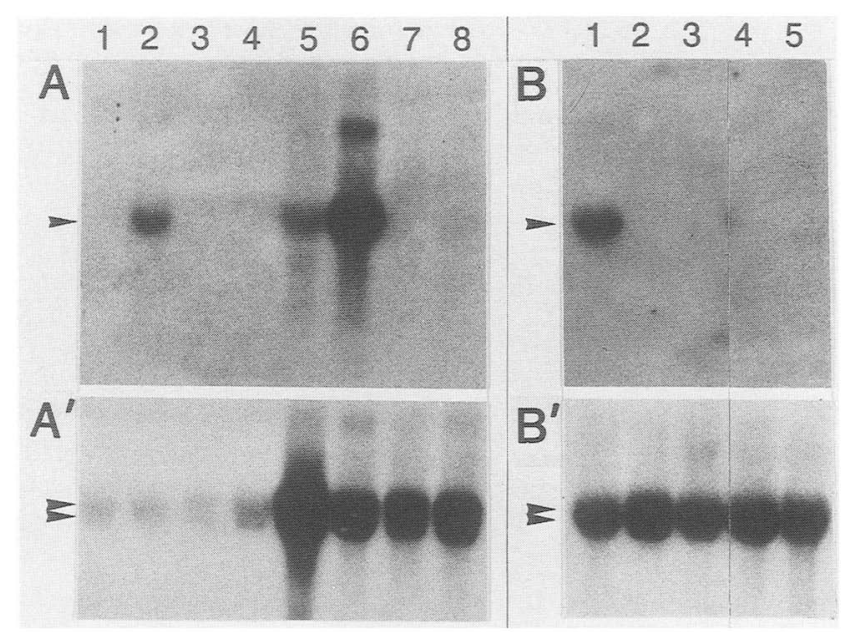

Figure 4. Northern blot analyses of twi expression in embryos descended from dorsal, pelle, easter, and Toll homozygous females. $\left(A ; A^{\prime}\right)$ twi expression in homozygous $d l$ embryos. (Lanes 1-4) Total RNA (20 $\mu \mathrm{g} /$ track); (lanes 5-8) poly(A) ${ }^{+}$RNA (20 $\mu \mathrm{g} / \mathrm{track})$. twi cDNA as probe $(A, 90 \mathrm{hr}$ exposure time), actin $5 \mathrm{C}$ probe as control on the same filter $\mid A^{\prime}, 3$-hr exposure time). Some twi RNA is detected in 0- to 2-hr wild-type embryos (lanes 1 and 5). The bulk of twi expression is in 2- to 4-hr wild-type embryos (lanes 2 and 6). twi RNA is about $1.7 \mathrm{~kb}$ long [the upper band in lane 6 is a cross reaction of the $t w i$ cDNA probe (unpublished)]. No twi expression is detected in $d l$ homozygous embryos. (Lanes 3 and 7) 0- to 2-hr embryo RNAs; (lanes 4 and 8) 2- to 4-hr embryo RNAs. $\left(B, B^{\prime}\right)$ Expression of $t$ wi in embryos descended from females homozygous for pelle, easter, Toll, and dl. About $20 \mu \mathrm{g}$ of total RNA extracted from 2- to 4-hr embryos was deposed in each lane and separated. These embryos descended from wild-type females (lane 1) and homozygous females for $d 1$ (lane 2), Toll-recessive (lane 3), pelle (lane 4), and easter (lane 5). The filter was hybridized to the twi cDNA probe $(B, 132-\mathrm{hr}$ exposure time). As a control, actin $5 \mathrm{C}$ was hybridized on the same filter to measure the amount of RNA loaded in each track $\left(B^{\prime}\right.$, overnight exposure time). Only the wild-type embryos (lane 1) show correct twi expression: No twi RNA can be detected in embryos descended from females mutated for $d l$ (lane 2), Toll-recessive (lane 3), pelle (lane 4), and easter (lane 5).

4-hr embryos developing from eggs laid by mutant females homozygous for pelle, easter, and Toll-recessive and probed it for the presence of twi transcripts (Fig. 4B). No $t w i$ RNA could be detected in RNA extracted from 2to 4-hr embryos descended from females homozygously mutant for Toll-recessive (lane 3), pelle (lane 4), or easter (lane 5), whereas approximately the same amount of RNA was loaded in each case (see Fig. 4B' for actin 5C hybridization as a control on the same filter); Figure $4 \mathrm{~B}$, lane 1, shows the level of twi RNA detected in wild-type 2- to 4-hr embryos, and lane 2 shows the twi expression in 2- to 4-hr embryos derived from eggs laid by homozygous $d l$ females in the same experiment.

\section{Discussion}

We have determined the localization of the transcripts of a gene, twi, which plays a crucial role at the time of 
the major germ layer decisions, that is, at the period of the subdivisions of the dorso-ventral pattern. We show that early in development, twi transcripts accumulate specifically in the cells forming the ventral furrow at gastrulation and, later, in the cells belonging to the presumptive mesoderm. However, the present in situ hybridization data do not exclude a low level of expression, close to the background, in the other cells of the embryos. The stages where clear hybridizations are seen on the tissue sections correspond to the period of maximum transcript accumulation determined by Northern blot analyses (Thisse et al. 1987). Because the genetic studies have shown a lack of mesoderm differentiation in twi embryos, it is not surprising that the twi transcripts are found in the cells of the future mesoderm. However, in the case of $d l$ embryos (which also do not differentiate mesoderm), Steward et al. (1985) found that $d l$ transcripts are distributed uniformly within the oocyte and suggested that this could also be the case within the embryos. Thus, these two genes have obviously different functions, although they share similar mutant phenotypes and possibly act on the same developmental process.

The finding that the expression of $t w i$ is regulated in the time [around gastrulation (Thisse et al. 1987)] and in space (within the presumptive mesodermal cells) raises the question of how this regulation is achieved. Candidates as regulatory genes are those acting before the time of expression of twi and known to be involved in the dorso-ventral pattern establishment of the embryo, that is, the dorsal group of maternal genes and the zygotic genes sna or Hind-d (the last belonging to the decapentaplegic-complex). For the maternal group of dorsalizing genes, we have demonstrated that mutations in either $d l$, pelle, easter, or Toll abolish the expression of twi. Thus, the induction of twi expression requires these other gene activities, at least. At least one dose of $\mathrm{dl}^{+}$ gene in the females appears to be necessary for the transcription of twi.

Our results do not allow us to establish any hierarchy between these genes, nor do they indicate whether any of these maternal genes controls twi expression directly. However, if the working model of Anderson et al. (1985a) is correct, $d l$ or Toll would be the best candidates as regulatory genes for $t w i$, because they are active at a later stage during oogenesis than pelle or easter. For $d l$, fate-mapping studies at the cellular blastoderm stage on $d l^{D}$ performed by Nüsslein-Volhard et al. (1980) have shown that the ventral cells that would normally form the mesoderm in wild-type embryos are reprogrammed and develop as ventral hypoderm in $d l^{D}$ embryos. Thus, at least in $d l$ embryos, the ventral cells in which twi should be expressed appear to survive and divide, but they do not differentiate as mesoderm cells. In addition, the twi mutation appears to enhance the phenotype caused by $d l$ mutants, as twi heterozygous embryos from heterozygous $d l$ females exhibit a mutant dorsalized phenotype at $25^{\circ} \mathrm{C}$, whereas at that temperature, $t w i^{+}$embryos from heterozygous $d l$ females have a wild-type phenotype. Thus, the lack of mesoderm formation in $d l, t w i$ double heterozygous embryos suggests that the $t w i^{+}$product is necessary quantitatively (even if not sufficient alone) for mesoderm formation (as the same dose of $\mathrm{dl}^{+}$product is present in simple $\mathrm{dl}^{+}$heterozygous embryos that differentiate mesoderm). Because the $d l^{1}$ allele is thought to be amorphic (Nüsslein-Volhard et al. 1980; Simpson 1983), it seems unlikely that the observed differences in the expression of $t w i$ in embryos derived from eggs laid by homozygous and heterozygous $d l$ females could be due to a "repression" by an altered mutant $d l$ RNA or protein. A protein translated from the dl RNA may be necessary (but not necessarily sufficient) for the induction of the expression of $t w i$. As in late embryos, the rescuing activity for the $d l$ phenotype is located in the ventral part of the embryos (Santamaria et al. 1983), and our present data show that the accumulation of the twi transcripts appears to begin in the ventral part of the embryo; the $d l$ protein may, in fact, be directly responsible for switching on twi transcription.

Genetic studies (Simpson 1983) have shown a specific interaction between $d l$ and twi but not with any of the other dorsal-group maternal genes. However, genetic studies that lead to the detection of interactions between genes may be restricted to certain classes of interactions. For instance, they may detect only interactions where large amounts of the product of one gene are necessary for the correct expression of the second one. If so, some genes of the dorsal group (i.e., pelle or easter) that could also be responsible for correct expression of twi in a more subtle way, may not have been detected. To detect an interaction between such a maternal gene and $t w i$ may require tests of different combinations of weak alleles of the respective genes, which have not yet been performed.

The relations between maternal and zygotic genes implied in the same process have just begun to be studied. Here, we show that the lack of one "information" or product of the maternal genes prevents the expression of the zygotic twi gene. Therefore, the mutant phenotype of embryos developing from homozygous females mutant for maternal genes such as dorsal, easter, and so forth, does not seem to be a misinterpretation of maternal information by the zygotic $t w i$ gene, but, at least, the absence of the expression of the zygotic twi gene because of the lack of complete maternal information.

\section{Materials and methods}

Fly stocks and embryo isolations

Our Drosophila Oregon R strain was used for mass cultures to prepare wild-type RNAs and to collect staged embryos for in situ hybridizations or tissue sections.

Homozygous females for dorsal, pelle, easter, and Toll-recessive were sorted individually from $d l^{1}$, pelle $e^{385}$, and easter ${ }^{D R}$ strains. For Toll, we crossed $D f(3 R) T o l l^{3 Q R X}$ and Toll ${ }^{5 B R E Q}$ to obtain homozygous females.

\section{In situ hybridizations}

DNA probes were nick-translated with $\left[{ }^{3} \mathrm{H}\right] \mathrm{dNTP}$. Tissue sectioning, hybridizations, and washes were done exactly as described by Hafen et al. (1983). In all experiments, we used an 
EcoRI-BamHI fragment of $530 \mathrm{bp}$ from the $3^{\prime}$ part of the twi cDNA, subcloned in a pEMBL vector (Dente et al. 1983), as a ${ }^{3} \mathrm{H}$ probe. The fragment was isolated electrophoretically before labeling. This fragment does not contain a repeated sequence. Sections were exposed for autoradiography from 10 days to 1 month (the longer exposures led to a higher background expression). Controls of the same exposure times were performed with the pEMBL vector alone, which gave a uniform hybridization all over the sections. A 10-day exposure time resulted in a weak signal only in the mesodermal cells. Wild-type embryos were used throughout.

Photomicrographs used Ilford HP5 film and are presented so that the anterior is to the left and dorsal is uppermost.

\section{Nucleic acid extractions and analyses}

RNAs were extracted from staged embryos as described by Auffray and Rougeon (1980). Poly(A) + RNAs were prepared and Northern blotting was done according to Maniatis et al. (1982).

\section{Acknowledgments}

We are grateful to P. Chambon for encouragement and helpful discussions. We thank C. Nüsslein-Volhard and P. Simpson for suggestions and comments, G. Richards for critically reading the manuscript, B. Boulay and C. Werle for help with the figures, and A. Ney for typing the manuscript. This work was supported by grants from the CNRS, the INSERM, the Fondation pour la Recherche Médicale, the Ministère de la Recherche et de la Technologie, and the Association pour la Recherche sur le Cancer.

\section{References}

Anderson, K. and C. Nüsslein-Volhard. 1984a. Genetic analysis of dorso-ventral embryonic pattern in Drosophila. In Primers in developmental biology (ed. G. Malacinski and S. Bryant), pp. 269-289. Macmillan, New York.

- 1984b. Information of the dorso-ventral pattern of Drosophila embryo is stored as maternal mRNA. Nature 311: 223-227.

.1986. Dorsal group genes of Drosophila. In Gametogenesis and the early embryos, pp. 177-194. Alan R. Liss, New York.

Anderson, K.V., G. Jürgens, and C. Nüsslein-Volhard. 1985. Establishment of dorso-ventral polarity in the Drosophila embryo: Genetic studies on the role of the Toll gene product. Cell 42: 779-790.

Auffray, C. and F. Rougeon. 1980. Purification of mouse immunoglobulin heavy chain messenger RNAs from total myeloma tumor RNA. Eur. J. Biochem 107: 303-314.

Campos-Ortega, J.A. and V. Hartenstein. 1985. The embryonic development of D. melanogaster. Springer-Verlag, BerlinHeidelberg.

Dente, L., G. Cesareni, and R. Cortese. 1983. pEMBL: A new family of single-stranded plasmids. Nucleic Acids Res. 11: $1645-1655$.

Lohs-Schardin, M., C. Cremer, and C. Nüsslein-Volhard. 1979. A fate map for the larval epidermis of Drosophila melanogaster: Localized cuticle defects following irradiation of the blastoderm with an ultraviolet laser microbeam. Dev. Biol. 73: 239-255.

Maniatis, T., E.F. Fritsch, and J. Sambrook. 1982. Molecular cloning: A laboratory manual. Cold Spring Harbor Laboratory, Cold Spring Harbor, New York.
Nüsslein-Volhard, C. 1977. Genetic analysis of pattern formation in the embryo of Drosophila melanogaster. Wilhelm Roux's Arch. Dev. Biol. 183: 249-268.

- 1979. Maternal effect mutations that alter the spatial coordinates of the embryo of Drosophila melanogaster. In Determination of spatial organization. (ed. G. Subtelney and I.R. Koenigsberg), pp. 185-211. Academic Press, New York.

Nüsslein-Volhard, C., M. Lohs-Schardin, K. Sander, and C. Cremer. 1980. A dorso-ventral shift of embryonic primordia in a new maternal effect mutant of Drosophila. Nature 283: $474-476$.

Nüsslein-Volhard, C., E. Wieschaus, and H. Kluding. 1984. Mutations affecting the pattern of the larval cuticle in Drosophila melanogaster. I. Zygotic loci on the second chromosome. Wilhelm Roux's Arch. Dev. Biol. 193: 267-282.

Santamaria, P. and C. Nüsslein-Volhard. 1983. Partial rescue of dorsal, a maternal effect mutation affecting the dorsal-ventral pattern of the Drosophila embryo, by the injection of wild-type cytoplasm. EMBO J. 2: 1693-1699.

Simpson, P. 1983. Maternal zygotic gene interactions involving the dorsal-ventral axis in Drosophila embryos. Genetics 105: 615-632.

Steward, R., L. Ambrosio, and P. Schedl. 1985. Expression of the dorsal gene. Cold Spring Harbor Symp. Quant. Biol. 50: 223-228.

Thisse, B., M. El Messal, and F. Perrin-Schmitt. 1987. The twist gene: Isolation of a Drosophila zygotic gene necessary for the establishment of dorso-ventral pattern. Nucleic Acids Res. 15: 3439-3453.

Zalokar, M. and I. Erk. 1976. Division and migration of nuclei during early embryogenesis of D. melanogaster. J. Microsc. Biol. Cell. 25: 97-106. 


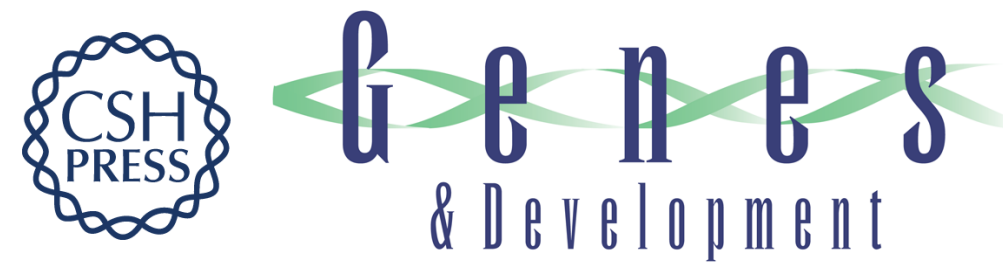

\section{Genes of the Drosophila maternal dorsal group control the specific expression of the zygotic gene twist in presumptive mesodermal cells}

Genes Dev. 1987, 1:

Access the most recent version at doi:10.1101/gad.1.7.709

References This article cites 13 articles, 2 of which can be accessed free at: http://genesdev.cshlp.org/content/1/7/709.full.html\#ref-list-1

License

Email Alerting

Receive free email alerts when new articles cite this article - sign up in the box at the top Service right corner of the article or click here.

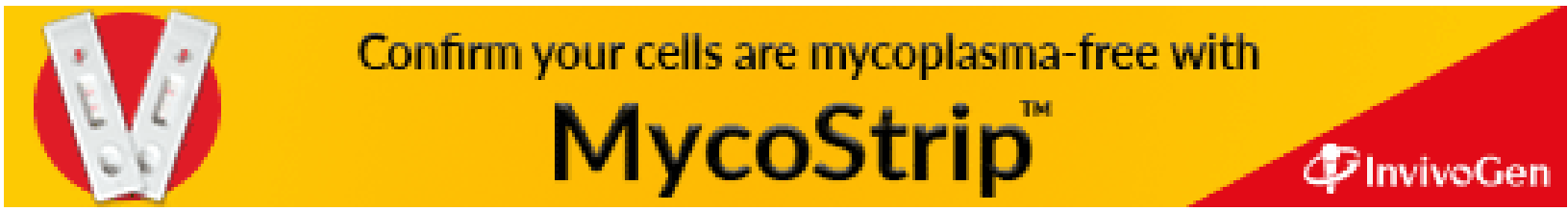

